\title{
O SUJEITO NA PSICANÁLISE E NA EDUCAÇÃO
}

\section{Maria Cecília Galletti Ferretti}

"Mas, é preciso insistir nào somente porque o uso, mas que a forma lógica dada a este saber (a ciência) inclui o modo

de comunicaçâo como suturando o sujeito que ele implica".

(Lacan, 1965, p. 877)

[ acan endereça uma crítica contundente à ciência: ela sutura o sujeito ${ }^{1}$. Sutura designa a relação do sujeito com a cadeia da qual foi excluído, a ciência busca deixá-lo de lado, mas os efeitos de sua presença se farão sentir. A crítica de Lacan à ciência é de fundamental interesse para a educação, na medida em que se quer delimitar o seu campo.

Considera-se, com demasiada freqüência, que a educação resulta do entrecruzamento e da articulaçào das conquistas de disciplinas que gravitam em torno da ciência, constituindo-se assim, num campo interdisciplinar. Se nos perguntarmos pela implicaçào do projeto de uma ciência educacional, podemos dizer que "o empreendimento para universalizar e tornar científica a educação foi um projeto iluminista (...) facilitado ainda mais, no curso do século XIX, pelas emergentes disciplinas da Psicologia, da Sociologia e da Ciência Política. Essas ciências humanas estabeleceram, inicialmente de forma simples, mas com crescente sofisticação, as metodologias empíricas e cientificamente verificáveis que identificariam objetivamente sistemas sociais mais racionais, apropriados à modernidade, os quais as Ciências Físicas e suas concomitantes descobertas tecnológicas tinham facilitado" (Jones, 1995, p. 112).

Embora Lacan insira-se num projeto iluminista, propòe para a psicanálise

Psicanalista; membro da Escola Brasileira de Psicanálise; membro da Associação Mundial de Psicanálise; Doutoranda da FEUSP. 
uma formalização que difere daquele das ciências físicas. A crítica que faz à ciência, interessa de modo particular para o estabelecimento de um projeto educacional, já que não se trata de considerar a educação integrada às, assim chamadas, "ciências humanas", termo que Lacan critica por razões de fundo.

Aqueles que propõem para a educação o campo da interdisciplinaridade, na maioria das vezes, acostumaram-se a buscar na filosofia uma explicitação dos fundamentos do que preconizavam. Insiste-se, que cabe à filosofia uma reflexão e um esclarecimento sobre a teoria do sujeito que subjaz, seja à didática, seja à psicopedagogia. É fácil perceber que essas disciplinas partem, necessariamente, de uma teoria do conhecimento e que, além disso, essa teoria nem sempre é explicitada. Caberia, então, à filosofia, a tarefa desta explicitaçào.

Canguilhem, autor citado por Lacan em $A$ ciência e a verdade, quando se questiona sobre "O que é a psicologia?", ao criticar a visão instrumentalista da ciência no que concerne ao sujeito, objeta à psicologia a separação que ela opera em relação à filosofia. Canguilhem pede, na verdade, que a psicologia procure fundamentar-se no conhecimento filosófico para que adquira coerência entre os conceitos e reflita sobre a sua ética.

Mas, partir da psicanálise para a reflexão sobre o sujeito e sobre o estatuto da ciência, na sua relação com a educação é coisa de outra ordem. Lacan não fala como filósofo, utiliza a filosofia com extrema liberdade, tendo em vista a transmissão da psicanálise.

Ele nos fala como psicanalista que retira sua ética e seus fundamentos teóricos do funcionamento do aparato psicanalítico. Colette Soler, vai mostrar que insistiu "suficientemente sobre a posição epistêmica de Lacan, posição ética e epistêmica ao mesmo tempo, que consiste em encontrar seu apoio nas implicações da estrutura" (1988, p.17) e afirma também que a norma instaurada por Lacan "consiste, no fundo, em impulsionar até suas últimas conseqüências as implicações do dispositivo" (Soler, 1988, p.21).

Para a educação este ponto é importante, não lhe é indiferente o fato de que a "experiência psicanalítica forneça uma teoria e uma ética, cabendo afirmar que a dimensão clínica confunde-se com a epistemológica e vice-versa" (Lajonquière, 1994, p.58).

Se Lacan não fala como filósofo, mas a partir do aparato psicanalítico e além disso, faz uma crítica à ciência, como se coloca a psicanálise frente ao modelo científico de conhecimento?

A questào da cientificidade da psicanálise, é tema freqüente em Lacan. Ele dirá, por exemplo, que "não basta colocar em fórmulas uma ciência para que o problema seja resolvido, pois, uma falsa ciência, assim como uma verdadeira, pode ser posta em fórmulas. A questão, portanto, não é simples, uma vez que a psicanálise, como suposta ciência, aparece com características que podemos dizer problemáticas" (Lacan, 1979, p.17). 
As características problemáticas da psicanálise para que possa ser inserida no universo científico, não impedem, no entanto, que Lacan possa ser incluído no interior do "Século das Luzes". Sobre isso, podemos ler na contracapa dos Escritos: "É preciso haver lido esta compilação, para constatar que aí se segue um só debate, sempre o mesmo, já que, como se fez evidente, se reconhece por ser o debate das luzes".

Lacan, ao propor para a formalização da psicanálise, os matemas, o "discurso sem palavras", pensa na transmissão integral de que é capaz, a escrita. $O$ uso da linguagem matemática e o da lógica, aproximam a psicanálise de um pensamento científico, mas não do modelo experimental e positivista.

\section{A TEORIA DO SUJEITO E A CRÍTICA À CIÊNCIA}

A importante crítica feita pela psicanálise ao pensamento científico e que é fundamental para as questòes da educaçào, prende-se a uma teoria do sujeito. Dito de outro modo: é porque na psicanálise há uma determinada teoria do sujeito que o modelo científico e seus ideais, sào criticados.

Lacan é radical ao dizer que toda a teoria sobre o sujeito deve partir da descoberta freudiana. Ao falar sobre o novo estatuto do sujeito, estabelece como balizas, a castraçào e o desejo. É este sujeito que a ciência é acusada de suturar, enquanto que a psicanálise permitirá a ele, levar um saber à verdade.

No Seminário XI, Fançoise Dolto em uma intervençào, observa que nào vê como descrever a formaçào da inteligência antes dos três ou quatro anos, sem levar em conta os estágios do desenvolvimento. Lacan, responde que a "descriçào dos estágios, formadores da libido, nào deve ser referida a uma pseudo-maturação natural, que permanece sempre opaca. Os estágios se organizam em torno da angústia da castração" (Lacan, 1979, p.65). A introdução da sexualidade é traumatizante porque a angústia da castraçào incide sobre a, assim chamada, percepção.

Quanto ao desejo, Lacan dirá que é o "cogito freudiano", dando a ele o lugar pivo de toda a teoria sobre o sujeito. É no ponto do desejo que a ciência será inquirida. Ao perguntar pelo desejo do analista, estende a pergunta ao cientista: qual é o desejo presente na ciência moderna? A história da ciência mostra que essa pergunta só é feita emo momentos de crise; porque esperar que os efeitos da bomba atômica se façam sentir para perguntar pelo desejo da física moderna? Oppheimer, o cientista, visava o quê?? Vê-se que ética e descjo se mesclam, na psicanálise.

Lacan percorre a história da filosofia a propósito da questào do sujeito e do desejo; nos diz que Sócrates foi o primeiro a formular que nada sabia, "a não ser o que diz respeito ao desejo" (Lacan,1979,p.20). Ponto teórico fundamental para que possamos compreender a crítica de Lacan à ciência e consequentemente compreendermos a posiçào da educação neste debate: o desejo nào é posto em posiçào de subjetividade por Sócrates, mas em posiçào de objeto. Também em Freud, mostrará Lacan, trata-se do desejo como oljeto.

Se Lacan assim vê a filosofia socrática, considera, por outro lado, que Aristóteles quando segue pela via dos pré-socráticos estabelece "um caminho que a experiência analítica impòe que se retifique, porque ele evita o caminho da castraçào" (Lacan, 1979, p.78).

Mas, suas referências a esta problemática, nào se dirigem apenas à filosofia antiga. Citando Merleau-Ponty, faz notar que há um avanço desse filósofo em direção à descoberta freudiana, mas 
no entanto, há um recuo. Cito Lacan: "as referências que ali se fazem, muito especialmente ao inconsciente psicanalítico, nos deixam perceber que ele estaria, talvez, se dirigindo para uma pesquisa original em relação à tradiçào filosófica, para essa nova dimensão da meditação sobre o sujeito que a análise permite, a nós, traçar" (Lacan, 1979, p. 82).

Lacan, ao mesmo tempo que acusa a ciência de esquecer a forma como nasceu, indica que a história do pensamento deve ser recuperada: a noçào de ciência verdadeira se degradou "na viragem positivista", onde as ciências experimentais serviam como modelo. Cito: "esta noçào provém de uma via errada da história da ciência, fundada sobre o prestígio de um desenvolvimento especializado da experiência" (Lacan, 1966, p.284).

Assim, há um desmascaramento da ilusão do projeto científico nos moldes positivistas, o que interessa de muito perto à educaçào. De qual sujeito fala o educador?

A crítica de Lacan à ciência é correlata à sua teoria sobre o sujeito. O educador nào deverá proceder como na ciência, onde as tentativas de suturar o sujeito acabam por "aferrolhar a verdade".

A ciência para se constituir, exige que se negue a Spaltung do sujeito. Em A ciência e a verdade, Lacan vai mostrar que a sutura do sujeito feita pela ciência, a reduçào pela qual procede, é uma reduçào que constitui propriamente seu objeto. Ele nos fala dos "dramas que vào por vezes até à loucura", desses sábios que vivem o impossível das crises da ciência. Foi preciso a psicanálise para renovar a questào do saber, ao evidenciar que há um saber que nào se salue.

Jacques-Alain Miller observa, em uma intervençào no Seminário $X I$, que "a diferença dos discursos que prece- dem seu surgimento, a ciência nào se funda na combinatória inconsciente. Ela se instaura, por estabelecer como inconsciente uma relaçào de não-relação. Ela é desconectada. O inconsciente nào desaparece dela, contudo, e suas incidências continuam ali a se fazer sentir" (1979, p.152).

As conexòes da psicanálise e as questôes da transmissão psicanalítica

As críticas de Lacan à ciência, no entanto, não pressupòem preconizar para a psicanálise um lugar isolado, tendo em vista os demais setores do conhecimento. A articulaçâo da psicanálise com as ciências afins foi algo previsto por Lacan, desde o momento em que medidas institucionais foram tomadas para a fundação de uma Escola, onde a formaçào de analistas tivesse lugar. "Era necessário propor um agrupamento para as pessoas que se dedicam à psicanálise, que fugisse a esse modelo clássico dos grupos que evitam o real, forcluindo-o ou mascarando-o. Ele "inventa" um agrupamento onde o destaque é o que se pode saber e transmitir da psicanálise. O termo escola privilegia a relação com o saber, enquanto que sociedade, o laço entre as pessoas" (Forbes, 1992, p.11).

As questòes referentes à transmissào - aqui, mais um elo com a educaçào - constituem temas freqüentes no âmbito psicanalítico. Quando se pensa na transmissão existente nos cartéis, uma forma privilegiada na psicanálise, pergunta-se pelo tipo de discurso que aí impera. Também, as mudanças provocadas no sujeito através do tratamento analítico, embora em tudo se distancie de uma transferência de conhecimento, sào efeitos de um elo social estruturado pelo matema do discurso analítico. Discurso este, onde se visa a levar um saber a verdade. Necessariamente, ao abordarmos as relaçoes da educaçào com a psicanálise e destas com a ciência, te- 
mos que adentrar os lugares e os termos do discurso analítico.

Além disso, o que se passa na supervisão psicanalítica em termos de "aprendizagem"? E com o sujeito que transmite e seu público? Essas indagaçòes constituem capítulo à parte. Lacan, em Televisão, afirma que fala do lugar do sujeito barrado, estando, o seu público, no lugar do objeto $a$, causa do desejo. Poderíamos preconizar para o professor o lugar do $\$$ e para os alunos, a posição de objeto $a$ ?

A questão da transmissão na Escola, é tratada por Lacan como sendo de extrema importância, na medida em que uma prática, no caso, a analítica, nào pode ser aquela de uma experiência inefável. Deve-se "providenciar a divulgação dos princípios dos quais a praxis analítica vai tirar da ciência o seu estatuto".

Vê-se descle logo, que ele pòe em conexão a ciência e os princípios da prática analítica; dirá que assim como as ciências podem receber "inspiração complementar" da psicanálise, esta última poderá usufruir o que do "estruturalismo instaurado em certas ciências" (Lacan, 1964, p. 85), lhe for útil. Tratar-seá de desenvolver, no momento oportuno, o que significa utilizar-se do estruturalismo instaurado em certas ciências.

Lacan nos fala também de uma "ordem de afinidades desenhada pelas ciências, que denominamos conjeturais" (Lacan,1964,p.85). Desta forma, o tema das conexões da psicanálise nos toca de muito perto, quando buscamos refletir sobre a educação a partir do ponto de vista psicanalítico; como se posiciona a educaçào frente às ciências conjeturais?

\section{A CRIANÇA EDUCADA E O "EVENTO FREUD"}

A criança é tema privilegiado no âmbito educacional. É também no inte- rior da questão sobre o objeto, causa do desejo, que a criança pode ser considerada. O tema sobre o sujeito na psicanálise e na educação deve, necessariamente, abordar esse objeto que todo o sujeito um dia foi. O sujeito "tem que emergir da causa do desejo da mãe, ao menos da "causa" com o que este desejo estava feito (...), os dados clínicos que Lacan toma, estão destinados, sem dúvida, a indicar a importância primordial da acolhida realizada pela màe a esse que será seu produto" (Miller, 1987 , p. 178).

O conceito de objeto $a$, causa do desejo, adquire, na psicanálise, a força de um conceito fundamental. Além do mais, trata-se de um conceito de muita riqueza interdisciplinar: "a terapia familiar também percebe a funçào decisiva do que, em nossa linguagem, formulamos como "o que o sujeito foi para o Outro em sua ereção de ser vivo", responsável, por exemplo, pela tendência ao suicídio das crianças nào desejadas, assinalada por Lacan" (Miller, 1987, p. 178)

Porém, ao lado do par mãe-criança, a que fomos levados pelo conceito "objeto causa do desejo", importa igualmente à educação, outra dupla, a que se estabelece entre o pai e a criança. Freud, no texto Psicologia das massas e análise do eu, diz que, contrariamente ao que poderia parecer, não é a mãe o primeiro objeto de amor e sim, o pai.

Freud introduz na história do pensamento uma nova criança, ao mostrar que ela goza de maneira perversamente polimorfa, o que "faz subir à cena com essa criança suja é o pai, mas o pai enquanto inconsciente, isto é, a ser construído" (Clastres, 1991, p. 138).

Lacan vai apontar que o "evento Freud" é impensável antes da realização deste novo elo social em torno da criança educada...". Mas, antes de Freud, não se tratava da mesma criança. Essa crian- 
ça, "tal como acreditamos conhecê-la, tal como polariza hoje todas as atençòes dos educadores, dos psicólogos, dos médicos, dos analistas, essa criança nem sempre esteve nesse lugar" (Clastres, 1991, p. 137).

É apenas nos séculos XVI e XVII que surge a preocupaçào educativa. Na Idade Média, a criança nào tinha o lugar particular que passa a ter. No século XVIII, com a publicaçào do Emile de J.J. Rousseau, o "século das luzes" fez notar sua incidência na educaçào. "Esta obra fez com que seu ator fosse cognominado o Copérnico da Educaçào, na história da pedagogia, visando a reforma social através da educaçào" (Lima, 1975, p. 85).

Desse modo, a crítica que Lacan faz à ciência, assentada sobre o que é o sujeito para a psicanálise, pede que a ciência nào esqueça como nasceu, nào esqueça o seu passado. É preciso examinar o quanto as teorias educativas estào atreladas aos seus momentos históricos, revelando a concepção de sujeito aí subjacente.

Sua censura à ciência, faz com que os educadores revejam o estatuto epistemológico da educaçào, o lugar que ocupa frente a outros setores do conhecimento humano. E, deve-se ter em mente, que a crítica psicanalítica ao conhecimento científico, só é possivel porque há uma determinada concepcào sobre o sujeito. Por isso, a conexào estabelecida entre a psicanálise e a educaçào deve ser assunto de nossos dias.

\section{REFERENCIAS BIBLIOGRÁFICAS}

CLASTRES, G. (1991). A criança no adulto. In: MILLER, J. (org.) A criança no discurso analitico. Rio de Janeiro: Jorge Zahar, p. 1.3(6-1.40.

FORBES, J. (1992). A escola de Lacan. Do conceito à prática e as condicòes de sua efetuaçào. In: FORBES, J. (org.) A escola de Lacan: a formaçào do psicanalista e a transmissào da psicanálise. São Paulo: Papirus, p. 9-19.

FREUD, S. (1973). Psicologia de las masas y analisis del "yo". In: Obras Completas, v. III. Buenos Aires: Biblisteca Nueva, p. 2563-2610 [1921].

JONFS, 1). (1995). Foucault e a possibilidade de uma pedagogia sem redenção. In: SILVA. T. (org.) O sujeito da educaçào. Estudos foucaultianos. Petrópolis: Vozes, p.111-126.

LACAN, J. (1966). La science et la verité In: Ecrits. Paris: Seuil, p. 855-877.

LACAN. J. (1979). Seminário XI: Os quatro conceitos findamentais da psicanálise. Rio de Janeiro. Zahar [1964].

LACAN. J. (1996) Ato de fundaçâo. 21 de junho de 1964. In: Amucirio e textos estatutarios. Escola Brasileira de Psicanálise.

LIMA. G. (1975). O indivíduo e a sociedade nas perspectivals de J.J. Rousseau e de J. Dewey. Revista da Faculdade de Educaçào da thiversidade de Sào Paulo, vol. 1, n" 1, p. 85-105.

LAJONQUIËRE, L. (1994). Epistemologia e psicanálise: o estatuto do sujeito. Percurso. Relista de Psicanálise, v. VII, n" 13,p. 57-63. SILVA. T.T. (1995). O sujeito da educaçào. Estudos Foncaultianos. Petrópolis: Vozes.

MILler, J. A. (1987). Matemas I. Buenos Aires: Manantial.

SOLER, C. (1988). Finales de analisis. Buenos Aires: Manantial.

NOTA

1 Sobre o conceito de "sutura", Eric Laurent nos informa em Lacan y' los discursos, (Buenos Aires: Manantial, 1992) que ele nào existia no discurso de Lacan , até que J.A. Miller fizesse seu artigo "A sutura". Lacan imediatamente incorporou o conceito em "A ciência e a verdade". 